\title{
Impacts of chronic kidney disease and albuminuria on associations between coronary heart disease and its traditional risk factors in type 2 diabetic patients - the Hong Kong diabetes registry Xilin Yang1, Ronald C Ma1, Wing-Yee So1, Gary T Ko*2, Alice P Kong1,3, Christopher W Lam ${ }^{4}$, Chun-Shun $\mathrm{Ho}^{4}$, Clive S Cockram${ }^{1}$, Vivian C Wong ${ }^{5}$, Peter C Tong ${ }^{1,2}$ and Juliana C Chan ${ }^{1,2,3}$
}

\author{
Address: ${ }^{1}$ Department of Medicine and Therapeutics, The Chinese University of Hong Kong, Hong Kong SAR, China, ${ }^{2}$ Hong Kong Institute of \\ Diabetes and Obesity, The Chinese University of Hong Kong, Hong Kong SAR, China, ${ }^{3} \mathrm{Li}$ Ka Shing Institute of Health Sciences, The Chinese \\ University of Hong Kong, Hong Kong SAR, China, ${ }^{4}$ Department of Chemical Pathology, The Chinese University of Hong Kong, Hong Kong SAR, \\ China and ${ }^{5}$ Hospital Authority, Hong Kong SAR, China \\ Email: Xilin Yang - yang.xilin@cuhk.edu.hk; Ronald C Ma - rcwma@cuhk.edu.hk; Wing-Yee So - wingyeeso@cuhk.edu.hk; \\ Gary T Ko* - garyko@cuhk.edu.hk; Alice P Kong - alicekong@cuhk.edu.hk; Christopher W Lam - cwklam@cuhk.edu.hk; Chun- \\ Shun Ho - csho@cuhk.edu.hk; Clive S Cockram - cscockram@cuhk.edu.hk; Vivian C Wong - vwong@ha.org.hk; \\ Peter C Tong - ptong@cuhk.edu.hk; Juliana C Chan - jchan@cuhk.edu.hk \\ * Corresponding author
}

Published: 2 December 2007

Cardiovascular Diabetology 2007, 6:37 doi:10.1 186/1475-2840-6-37

This article is available from: http://www.cardiab.com/content/6/1/37

(c) 2007 Yang et al; licensee BioMed Central Ltd.

This is an Open Access article distributed under the terms of the Creative Commons Attribution License (http://creativecommons.org/licenses/by/2.0), which permits unrestricted use, distribution, and reproduction in any medium, provided the original work is properly cited.

\begin{abstract}
Background: Glycated haemoglobin $\left(\mathrm{HbA}_{\mathrm{Ic}}\right)$, blood pressure and body mass index $(\mathrm{BMI})$ are risk factors for albuminuria, the latter in turn can lead to hyperlipidaemia. We used novel statistical analyses to examine how albuminuria and chronic kidney disease (CKD) may influence the effects of other risk factors on coronary heart disease (CHD).
\end{abstract}

Methods: A prospective cohort of 7067 Chinese type 2 diabetic patients without history of CHD enrolled since 1995 were censored on July $30^{\text {th }}, 2005$. Cox proportional hazard regression with restricted cubic spline was used to auto-select predictors. Hazard ratio plots were used to examine the risk of $\mathrm{CHD}$. Based on these plots, non-linear risk factors were categorised and the categorised variables were refitted into various Cox models in a stepwise manner to confirm the findings.

Results: Age, male gender, duration of diabetes, spot urinary albumin: creatinine ratio, estimated glomerular filtration rate, total cholesterol (TC), high density lipoprotein cholesterol (HDL-C) and current smoking status were risk factors of CHD. Linear association between TC and CHD was observed only in patients with albuminuria. Although in general, increased HDL-C was associated with decreased risk of CHD, full-range HDL-C was associated with $\mathrm{CHD}$ in an A-shaped manner with a zenith at $1.1 \mathrm{mmol} / \mathrm{L}$. Albuminuria and CKD were the main contributors for the paradoxically positive association between HDL-C and CHD for HDL-C values less than $1.1 \mathrm{mmol} /$ L.

Conclusion: In type 2 diabetes, albuminuria plays a linking role between conventional risk factors and CHD. The onset of CKD changes risk associations between lipids and CHD. 


\section{Background}

Coronary heart disease (CHD) is one of the leading causes of premature death [1]. Patients with type 2 diabetes have a 2-4 fold increased risk of CHD compared to those without [2]. The United Kingdom Prospective Diabetes Study (UKPDS) has identified hypertension, hyperglycaemia, high low-density-lipoprotein cholesterol (LDL-C), low high-density-lipoprotein cholesterol (HDL-C) and smoking status as major risk factors of CHD [3].

Recent studies have confirmed that albuminuria is another strong risk factor for cardiovascular disease [4-7]. This association holds true for albuminuria which occurs early in life [8]. Glycated haemoglobin $\left(\mathrm{HbA}_{1 \mathrm{c}}\right)$, blood pressure (BP), HDL-C, smoking and body mass index (BMI) are promoters of albuminuria [9]. The latter has been shown to increase the likelihood of high TC and LDL-C levels in a graded fashion [10]. While this relationship may partly explain the increased risk of CHD in patients with CKD [11], in patients with end-stage renal disease (ESRD), most studies point to low HDL-C but not high LDL-C as risk factors for cardiovascular diseases (CVD) [12].

Although there is some evidence suggesting possible linear risk relationships between $\mathrm{HbA}_{1 \mathrm{c}^{\prime}} \mathrm{BP}$, LDL-C, HDL-C and CHD [3], the linearity of these associations have never been rigorously examined. In this study, we used a non-linear approach to examine the possible impacts of albuminuria and CKD on conventional risk factors and new onset of CHD in a large prospective cohort of Chinese Type 2 diabetic patients.

\section{Methods \\ Subjects}

The Prince of Wales Hospital is a regional hospital which serves a population of 1.2 million in Hong Kong. The Hong Kong Diabetes Registry was established in 1995 and enrols 30-50 ambulatory diabetic patients each week. The referral sources included general practitioners, community and specialty clinics and patients discharged from hospitals. Enrolled patients with hospital admissions within 6-8 weeks prior to assessment accounted for less than $10 \%$ of all referrals. The 4 -hour assessment of complications and risk factors was performed on an outpatient basis, modified from the European DIABCARE protocol [13]. Once a diabetic subject had undergone the comprehensive assessment, he/she was considered to have entered this study cohort and would be followed up till death. The study was approved by the Clinical Research Ethics Committee, Chinese University of Hong Kong. The study complied with the Declaration of Helsinki and written informed consent was obtained from all patients.
Clinical endpoints including discharge diagnoses of hospital admissions and mortality were censored on $30^{\text {th }}$ July 2005. Details of hospital admissions were retrieved from the Hong Kong Hospital Authority Central Computer System which records admissions to all public hospitals in Hong Kong (accounting for 95\% hospital beds in Hong Kong). These databases were matched by a unique identification number, the Hong Kong Identity Card number, which is compulsory for all residents in Hong Kong.

Hospital discharge summaries as coded by the International Classification of Diseases, Ninth Revision (ICD-9), were used to identify first CHD. CHD was defined as (1) nonfatal myocardial infarction (code 410), (2) nonfatal ischemic heart disease (code 411-414) and (3) death due to CHD (not including death due to heart failure). Follow-up time was calculated as the period from enrolment to the first CHD event, death or $30^{\text {th }}$ July 2005, whichever came first.

From 1995 to 2005,7920 diabetic patients were enrolled in the Registry. Among them, 332 with Type 1 diabetes defined as acute presentation with diabetic ketoacidosis, heavy ketonuria $(>3+)$ or continuous requirement of insulin within 1 year of diagnosis [14], and 5 with uncertain type 1 diabetes status, were excluded from the analysis. Forty-nine were excluded due to non-Chinese or unknown nationality. Four hundred and sixty-seven patients were further excluded for having a past history of CHD (including heart failure) at enrolment. A total of 7067 Chinese type 2 diabetic patients without history of CHD and heart failure at baseline were included in this analysis.

\section{Clinical measurements}

Details of assessment methods, definitions and laboratory assays have been previously described $[15,16]$. On the day of assessment, patients attended the centre after at least 8 hours of fasting and underwent anthropometric measurements and laboratory investigations. We used the Modification of Diet in Renal Disease (MDRD) re-calibrated for Chinese [17] to estimate GFR expressed in $\mathrm{ml} / \mathrm{min}$ per $1.73 \mathrm{~m}^{2}$ :

$$
\begin{gathered}
\mathrm{eGFR}=186 \times[\mathrm{SCR} \times 0.011]^{-1.154} \times[\text { age }]^{-0.203} \times[0.742 \mathrm{if} \\
\text { female }] \times 1.233
\end{gathered}
$$

where SCR is serum creatinine expressed as $\mu \mathrm{mol} / \mathrm{l}$ (originally in $\mathrm{mg} / \mathrm{dL}$, now converted to $\mu \mathrm{mol} / \mathrm{l}$ ) and 1.233 is the coefficient for Chinese. Peripheral arterial disease (PAD) was defined by the absence of foot pulses on palpation, confirmed by Doppler ultrasound examination of the ankle:brachial ratio $<0.90$ or treatment for PAD. Chronic kidney disease was defined as eGFR $<60 \mathrm{ml} / \mathrm{min}$ per 1.73 $\mathrm{m}^{2}$. Normoalbuminuria was defined as ACR $<2.5 \mathrm{mg} /$ 
$\mathrm{mmol}$ in male and $<3.5 \mathrm{mg} / \mathrm{mmol}$ in female and microalbuminuria, between $2.5 \mathrm{mg} / \mathrm{mmol}$ (male) or $3.5 \mathrm{mg} /$ mmol (female) and $25 \mathrm{mg} / \mathrm{mmol}$, macroalbuminuria, $\geq 25-150 \mathrm{mg} / \mathrm{mmol}$. Due to its high risk nature, ACR $\geq 150$ $\mathrm{mg} / \mathrm{mmol}$ was considered as a separate group (see results).

\section{Statistical analyses}

The Statistical Analysis System (SAS, Release 9.10) was used to perform the statistical analysis (SAS Institute Inc., Cary, USA). In order to detect any thresholds, Restricted Cubic Spline (RCS) with 4 knots (i.e. 1 term decomposed into 3 terms: $\mathrm{x}, \mathrm{x}_{1}$ and $\mathrm{x}_{2}$ ) [18] and Cox proportional hazard regression with the stepwise algorithm $(\mathrm{p}<0.05$ for entry and stay) were used to obtain a group of significant predictors of CHD. The method on how to use RCS in Cox proportionality has been described in detail by Harrell [18]. The detailed algorithm on how to use a stepwise algorithm in spline Cox regression models has been described elsewhere [19].

Candidate variables at enrolment selected by the spline Cox model included systolic/diastolic blood pressure (BP), $\mathrm{HbA}_{1 \mathrm{c}^{\prime}} \mathrm{BMI}$, waist circumference, blood haemoglobin (Hb), white blood cells (WBC) count, HDL-C, LDL-C, triglyceride (TG), total cholesterol and drug usage (Table 1). After several auto-selection cycles [19], spot urine ACR and eGFR were also included in the final model.

In exploratory analysis, we calculated hazard ratio (HR) changes over full-ranges of baseline risk factors before and

Table I: Baseline clinical and biochemical characteristics of 7067 Chinese Type 2 diabetic patients with no past history of coronary heart disease (CHD)

\begin{tabular}{|c|c|c|c|c|c|}
\hline & \multicolumn{4}{|c|}{ Development of $\mathrm{CHD}$ before the censoring date } & \multirow[b]{3}{*}{$P$ value } \\
\hline & \multicolumn{2}{|l|}{ No $(n=6716)$} & \multicolumn{2}{|l|}{ Yes $(n=351)$} & \\
\hline & median or $\%$ & IQR & median or $\%$ & IQR & \\
\hline Follow-up time (years) & 5.58 & $2.97-7.89$ & 2.77 & $1.48-5.28$ & $<0.001$ \\
\hline Male & $45.0 \%$ & 1 & $51.9 \%$ & 1 & $0.012 \dagger$ \\
\hline \multicolumn{6}{|l|}{ Smoking status: } \\
\hline Current smoker & $20.1 \%$ & I & $29.1 \%$ & I & $0.057 \dagger$ \\
\hline Ex smoker & $13.2 \%$ & 1 & $18.2 \%$ & 1 & \\
\hline Age (years) & 56 & $46-67$ & 64 & $54-70$ & $<0.001 \neq$ \\
\hline Sex adjusted waist circumference $(\mathrm{cm})^{*}$ & 55.9 & 0.16 & 61.9 & 0.72 & $<0.001 \ddagger$ \\
\hline Body mass index $\left(\mathrm{kg} / \mathrm{m}^{2}\right)$ & 24.7 & $22.4-27.3$ & 24.6 & $22.7-26.7$ & $0.748 \ddagger$ \\
\hline Known duration of diabetes (year) & 5 & $1-10$ & 9 & $4-14$ & $<0.001 \ddagger$ \\
\hline Systolic blood pressure (mmHg) & 134 & $12|-| 48$ & $|4|$ & $130-155$ & $<0.001 \ddagger$ \\
\hline Diastolic blood pressure $(\mathrm{mmHg})$ & 76 & $69-83$ & 78 & $70-85$ & $<0.001 \ddagger$ \\
\hline Peripheral arterial disease & $5.4 \%$ & 1 & $13.7 \%$ & 1 & $<0.001 \dagger$ \\
\hline Retinopathy & $25.6 \%$ & l & $42.5 \%$ & l & $<0.001 \dagger$ \\
\hline Sensory neuropathy & $25.5 \%$ & 1 & $32.2 \%$ & 1 & $0.005 \dagger$ \\
\hline Glycated haemoglobin (\%) & 7.3 & $6.4-8.6$ & 7.6 & $6.6-9.3$ & $<0.001 \ddagger$ \\
\hline Blood haemoglobin $(\mathrm{g} / \mathrm{L})$ & 13.8 & $12.8-14.9$ & 13.6 & $12.4-14.7$ & $0.019 \ddagger$ \\
\hline Spot urinary ACR $(\mathrm{mg} / \mathrm{mmol})$ & 1.88 & $0.75-9.81$ & 7.65 & $1.61-72.3$ & $<0.001 \neq$ \\
\hline $\begin{array}{l}\text { Increased albuminuria (ACR } \geq 3.5 \mathrm{mg} / \mathrm{mmol} \text { in } \\
\text { female } \& \geq 2.5 \mathrm{mg} / \mathrm{mmol} \text {.in male) }\end{array}$ & $41.2 \%$ & 1 & $64.9 \%$ & 1 & $<0.001 \neq$ \\
\hline eGFR $\left(\mathrm{ml} / \mathrm{min} / 1.73 \mathrm{~m}^{2}\right)$ & 105.8 & $84.9-127.5$ & 89.8 & $66.0-112.9$ & $<0.001 \ddagger$ \\
\hline eGFR $<60 \mathrm{ml} / \mathrm{min} / \mathrm{l} .73 \mathrm{~m}^{2}$ & $9.3 \%$ & 1 & $18.5 \%$ & 1 & $<0.001^{\top}$ \\
\hline Low-density lipoprotein cholesterol (mmol/l) & 3.10 & $2.50-3.80$ & 3.52 & $2.9-4.2$ & $<0.001 \ddagger$ \\
\hline High-density lipoprotein cholesterol (mmol/l) & 1.25 & $1.05-1.50$ & 1.14 & $0.99-1.37$ & $<0.001 \ddagger$ \\
\hline Triglyceride (mmol/L) & 1.37 & $0.96-2.06$ & 1.55 & $1.11-2.18$ & $<0.001 \ddagger$ \\
\hline Total cholesterol (mmol/L) & 5.20 & $4.50-5.90$ & 5.54 & $4.85-6.30$ & $<0.001 \dagger$ \\
\hline \multicolumn{6}{|l|}{ Baseline use of drugs: } \\
\hline Oral anti-diabetic drugs & $60.9 \%$ & l & $59.0 \%$ & l & $0.448 \dagger$ \\
\hline Anti-hypertensive drugs & $33.2 \%$ & l & $43.0 \%$ & l & $<0.001 \dagger$ \\
\hline Insulin & $17.0 \%$ & I & $25.9 \%$ & l & $<0.001 \dagger$ \\
\hline Lipid lowering drugs & $12.3 \%$ & I & $13.7 \%$ & l & $0.450 \dagger$ \\
\hline ACEI or ARB & $20.0 \%$ & l & $25.1 \%$ & l & $0.022 \dagger$ \\
\hline
\end{tabular}

$\mathrm{IQR}$, inter-quartile range; eGFR, estimated glomerular filtration rate; ACEI, Angiotensin-converting enzyme inhibitors; ARB, angiotensin II receptor blockers; ACR, albumin:creatinie ratio; *, derived from analysis of covariance; $\dagger$, derived from Chi-square text; $\ddagger$, derived from Wilcoxon twosample test. 
after adjustment for eGFR and ACR, in order to observe the impacts of albuminuria and CKD on these risk associations. Hazard ratio between two points of variable $\mathrm{X}_{\mathrm{i}}$ can be estimated by $\exp \left(\mathrm{y}_{2}-\mathrm{y}_{1}\right)$, where $\mathrm{y}_{1}$ and $\mathrm{y}_{2}$ are the corresponding RCS function values of two $\mathrm{X}_{\mathrm{i}}$ points. In this study, the $25^{\text {th }}$ or $75^{\text {th }}$ percentile (for near linear relationship) or zenith points (for non linear relationship) of baseline variables were chosen as the reference point $\left(\mathrm{y}_{1}\right)$ to estimate $\mathrm{HR}$ of other points of baseline variable $\mathrm{X}_{\mathrm{i}}\left(\mathrm{y}_{2}\right)$. Here, $\mathrm{y}\left(\mathrm{y}_{1}\right.$ and $\left.\mathrm{y}_{2}\right)$ was the RCS function value of $\mathrm{X}_{\mathrm{i}}$, which was calculated by the formula: the spline function value of $x_{i}=\beta x+\beta x_{1}+\beta x_{2}$, where $\beta, \beta_{1}$ and, $\beta_{2}$ were estimated by applying $\mathrm{x}, \mathrm{x}_{1}$ and $\mathrm{x}_{2}$ as covariates in Cox models.

We then categorised significant continuous risk factors identified in the HR plots and used Cox regression analysis to confirm the findings in the risk curve analysis. Proportionals hazards assumption and functional form were checked using Supremum test [20], which is implemented using ASSESS statement in the SAS procedure PROC PHREG. A p-value of $<0.05$ for two-sided tests was considered to be statistically significant.

\section{Results}

\section{Study population and predicting models}

At enrolment, the median age of the cohort was 57 years (interquartile range [IQR]: 46-67 years) with a median disease duration of 5 (IQR: $1-11$ ) years. During a median follow-up period of 5.40 (IQR: 2.87-7.81) years, 351 $(4.97 \%)$ patients developed incident CHD giving an incidence rate of CHD of 9.28 (95\% CI: 8.31-10.24) per 1000 person-years. During the follow-up period, 681 (9.64\%) patients died. Of these, 47 deaths were due to fatal CHD (included in the 351 events, CHD as the principal diagnosis). Patients who developed CHD were older, had longer duration of diabetes, more unfavourable lipid profile (LDL-C, HDL-C and TG), worse renal function, higher $\mathrm{HbA}_{1 \mathrm{c}}$, urinary ACR and WBC, lower $\mathrm{Hb}$ and were more likely to be treated with insulin and antihypertensive drugs at baseline that those who did not (Table 1).

The spline Cox model selected sex, smoking status (current smoker/ex-smoker), use of angiotensin-converting enzyme inhibitors (ACEI)/angiotensin II receptor blockers (ARB) and spline terms of age, duration of diabetes, TC, HDL-C, blood $\mathrm{Hb}$ and insulin use at enrolment (Model 1). Blood $\mathrm{Hb}(\mathrm{p}=0.1709)$ and insulin use $(\mathrm{p}=$ 0.1710 ) were no longer significant after further inclusion of spline term of eGFR, while all other variables remained significant. Further adjusting for spline term of ACR ( $\mathrm{p}$ for $\mathrm{ACR}=0.0041)$ did not change the significance of other variables in the model.

\section{Risk factors of coronary heart disease}

Estimated GFR was negatively associated with incident CHD (Figure 1 and Table 2). The HR for CHD started to rise at the trough value of $100 \mathrm{ml} / \mathrm{min}$ per $1.73 \mathrm{~m}^{2}$, and rapidly from $60 \mathrm{ml} / \mathrm{min}$ per $1.73 \mathrm{~m}^{2}$ downwards. The HR of ACR for CHD increased rapidly from 0 to $150 \mathrm{mg} /$ mmol before reaching a plateau. Similar trends with ACR was observed in patients with normo, micro and macroalbuminuria and those with ACR $\geq 150 \mathrm{mg} / \mathrm{mmol}$ ( $\mathrm{p}<$ 0.05 for trend) (Figure 1 and Table 2).

There was near linear association between TC and CHD risk, which was attenuated by adjustment for eGFR and ACR (Figure 2a). Exclusion of patients with CKD led to a higher $\mathrm{HR}$ for those with high $\mathrm{TC}>5.0 \mathrm{mmol} / \mathrm{L}$. In patients without CKD, the HR of TC for CHD started to increase linearly from $5.0 \mathrm{mmol} / \mathrm{L}$ upwards. In patients with CKD, the shape of the risk curve was changed to one of "A-shaped" with a peak HR at $5.0 \mathrm{mmol} / \mathrm{L}$ (Figure 2b). In patients with normoalbuminuria, there was no significant association between TC and CHD (Figure 2c). Conversely, in patients with albuminuria, there was a linear relationship between TC and CHD risk.

HDL-C was associated with CHD in an A-shaped manner with a zenith at $1.1 \mathrm{mmol} / \mathrm{L}$ and a long tail on the right (Figure 3a). Both HDL-C $\geq 1.40 \mathrm{mmol} / \mathrm{L}$ and HDL-C $<0.80$ $\mathrm{mmol} / \mathrm{L}$ were associated with reduced risk of CHD (Table $3 b)$, which remained significant after adjusting for eGFR and ACR. The gradient of the HR curve accelerated more rapidly from very low level of HDL-C up to $1.1 \mathrm{mmol} / \mathrm{L}$ in the albuminuric group than in the non-albuminuric group. After excluding patients with CKD $(n=690)$, the negative risk association between CHD and HDL-C was significant for HDL-C $\geq 1.40 \mathrm{mmol} / \mathrm{L}(\mathrm{p}<0.001)$ but not for HDL-C level <0.80 mmol/L, $\mathrm{p}=0.127)$.

Blood $\mathrm{Hb}$ was associated with CHD risk in a linear manner (Figure 4). Excluding patients with CKD changed the shape of the HR curve with a shoulder value at $12.5 \mathrm{~g} / \mathrm{dL}$. Adjusting for eGFR also rendered the HR non significant for $\mathrm{Hb}<12.5 \mathrm{~g} / \mathrm{dL}$ versus. $\geq 12.5 \mathrm{~g} / \mathrm{dL}$ (Table 2 ). Risk of CHD increased with disease duration during the first 13 years, which then maintained at a high level (Figure 4 and Table 2). Old age, male gender, current smokers, use of ACEI/ARB and use of insulin were also associated with higher risk of CHD (Figure 4 and Table 2).

\section{Discussions}

Our study re-affirms previous observations that age, male gender, tobacco intake, long disease duration, high TC, low HDL-C, high ACR, and low eGFR were independent risk factors of $\mathrm{CHD}$ using conventional Cox regression analysis. The novelty of our analysis lies in its ability to demonstrate the powerful effects of albuminuria and CKD 

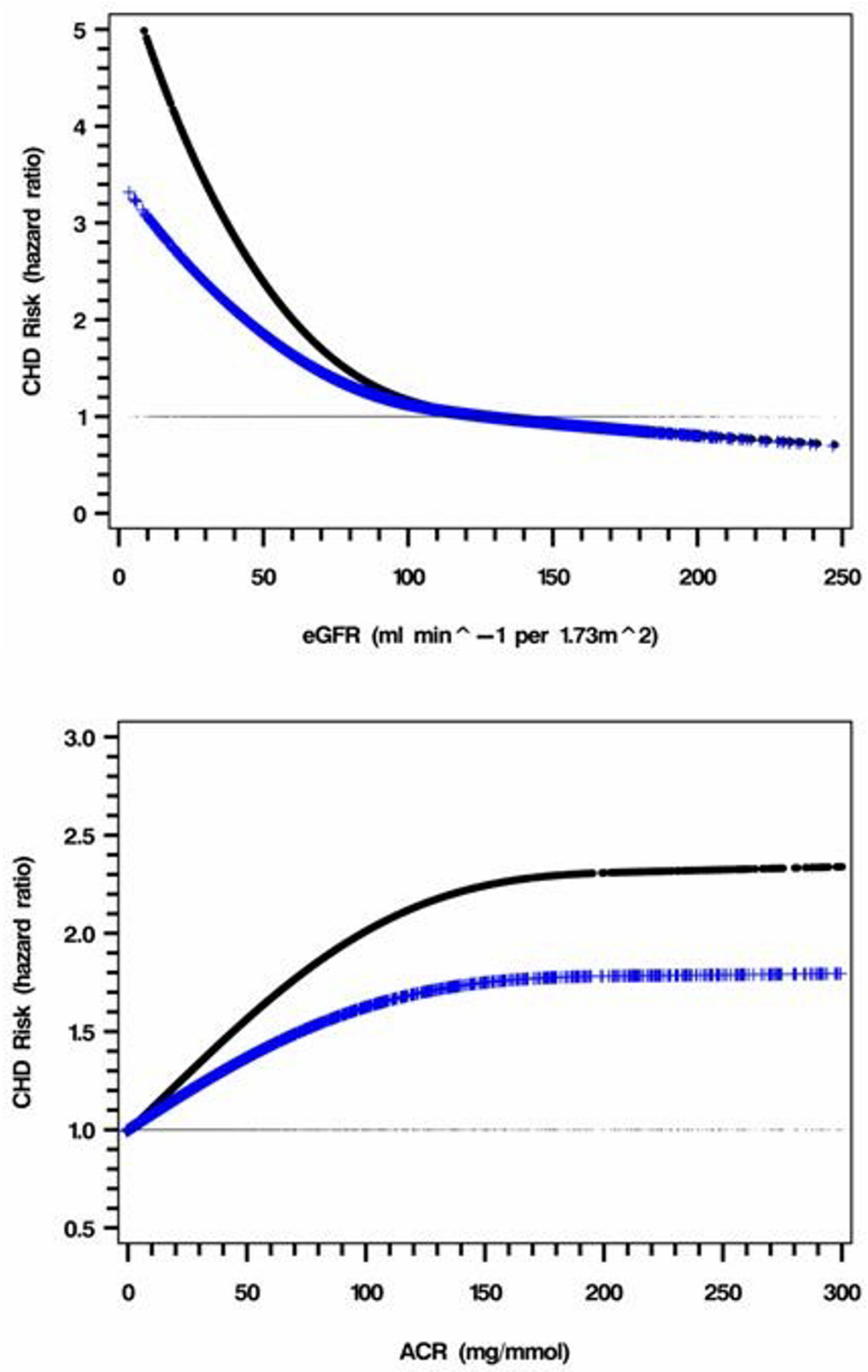

Figure I

Full range risk associations between CHD and eGFR/ACR. a. Black: adjusted for model I variables ( $P<0.05)$; Blue: further adjusted for ACR ( $p$ < 0.05). Model one variables include age, sex, and smoking status (current/ex), total cholesterol, HDL-C, Hb, eGFR and use of ACEI/ARB as well as use of insulin at enrolment. The hazard ratio was calculated using the $25^{\text {th }}$ percentiles, $75^{\text {th }}$ percentiles as the reference level. b. Black: adjusted for model I variables $(p<0.05)$; Blue: further adjusted for eGFR $(p<0.05)$. 
Table 2: Hazard ratios of significant baseline risk factors for coronary heart disease in type 2 diabetic patients (Model I) before and after inclusion of eGFR and ACR into the model.

\begin{tabular}{|c|c|c|c|c|c|c|}
\hline \multirow[b]{2}{*}{ Vaseline variables } & \multicolumn{2}{|l|}{ Model I† } & \multicolumn{2}{|l|}{ Model I plus eGFR $\ddagger$} & \multicolumn{2}{|c|}{ Model I plus eGFR \& ACRT } \\
\hline & Hazard ratio $(95 \% \mathrm{Cl})$ & $p$-value & Hazard ratio $(95 \% \mathrm{Cl})$ & $p$-value & Hazard ratio $(95 \% \mathrm{Cl})$ & $p$-value \\
\hline \multicolumn{7}{|l|}{ Age (year): } \\
\hline$<45$ vs. $45-59$ & $0.48(0.28-0.8 I)$ & 0.006 & $0.5 \mathrm{I}(0.30-0.86)$ & 0.012 & $0.50(0.29-0.84)$ & 0.010 \\
\hline$\geq 60$ vs. $45-59$ & $1.75(1.31-2.33)$ & $<0.001$ & $1.56(1.16-2.09)$ & 0.003 & $1.53(1.14-2.06)$ & 0.005 \\
\hline Female sex & $0.64(0.47-0.88)$ & 0.006 & $0.66(0.48-0.91)$ & 0.010 & $0.69(0.50-0.95)$ & 0.023 \\
\hline \multicolumn{7}{|l|}{ Smoking status: } \\
\hline Ex-smoking vs. never & $1.21(0.84-1.76)$ & 0.311 & I.I8 (0.8I-I.7I) & 0.384 & $1.13(0.78-1.64)$ & 0.5202 \\
\hline Current vs. never & $1.64(1.15-2.33)$ & 0.007 & $1.63(1.15-2.33)$ & 0.007 & $1.58(1.11-2.26)$ & 0.011 \\
\hline \multicolumn{7}{|l|}{$\begin{array}{l}\text { Duration of diabetes } \\
\text { (year): }\end{array}$} \\
\hline$<5$ vs. $\geq 13$ & $0.43(0.30-0.61)$ & $<0.001$ & $0.45(0.3 \mathrm{I}-0.64)$ & $<0.001$ & $0.49(0.34-0.7 I)$ & $<0.001$ \\
\hline $5-12$ vs. $\geq 13$ & $0.71(0.53-0.97)$ & 0.028 & $0.74(0.54-1.00)$ & 0.048 & $0.78(0.58-1.06)$ & 0.118 \\
\hline \multicolumn{7}{|l|}{$\begin{array}{l}\text { Blood haemoglobin (g/ } \\
\text { dL): }\end{array}$} \\
\hline$<12.5$ vs. $\geq 12.5 \mathrm{~g} / \mathrm{dL}$ & $1.58(1.16-2.15)$ & 0.004 & $1.35(0.98-1.87)$ & 0.067 & $1.22(0.88-1.69)$ & 0.238 \\
\hline \multicolumn{7}{|l|}{ HDL-C (mmol/L): } \\
\hline$<0.80$ vs. $0.80-1.39$ & $0.41(0.18-0.93)$ & 0.033 & $0.39(0.17-0.88)$ & 0.024 & $0.40(0.18-0.90)$ & 0.027 \\
\hline$\geq 1.40$ vs. $0.80-1.39$ & $0.52(0.38-0.70)$ & $<0.001$ & $0.54(0.39-0.73)$ & $<0.001$ & $0.56(0.4 I-0.76)$ & $<0.001$ \\
\hline $\begin{array}{l}\text { Total cholesterol } \\
(\mathbf{m m o l} / \mathbf{L})\end{array}$ & $1.22(1.11-1.36)$ & $<0.001$ & $1.20(1.08-1.32)$ & $<0.001$ & $1.12(1.00-1.25)$ & 0.045 \\
\hline Use of ACEI or ARB & $1.72(\mid .29-2.31)$ & $<0.001$ & $1.59(1.18-2.13)$ & 0.002 & $1.44(1.06-1.94)$ & 0.018 \\
\hline Use of insulin & $1.34(0.99-1.81)$ & 0.056 & $1.26(0.93-1.70)$ & 0.136 & $1.15(0.85-1.56)$ & 0.372 \\
\hline \multicolumn{7}{|l|}{$\begin{array}{l}\text { eGFR (ml/min per } 1.73 \\
\left.\mathrm{~m}^{2}\right):\end{array}$} \\
\hline$<60$ vs. $\geq 90$ & I & I & $1.90(1.27-2.84)$ & 0.002 & $1.37(0.89-2.10)$ & 0.152 \\
\hline $60-89.9$ vs. $\geq 90$ & I & I & $1.51(1.12-2.06)$ & 0.008 & $1.36(0.99-1.85)$ & 0.055 \\
\hline \multicolumn{7}{|l|}{$\begin{array}{l}\text { Urinary ACR (mgl } \\
\text { mmol) } \xi\end{array}$} \\
\hline Microalbuminuria & I & I & I & I & $1.34(0.97-1.85)$ & 0.075 \\
\hline Macroalbuminuria & I & l & I & I & $1.76(1.19-2.58)$ & 0.043 \\
\hline$A C R \geq 150 \mathrm{mg} / \mathrm{mmol}$ & I & I & I & I & $2.64(1.69-4.12)$ & $<0.001$ \\
\hline
\end{tabular}

eGFR, estimated glomerular filtration rate; ACR, albumin: creatinine ratio; HDL-C, high-density lipoprotein cholesterol; ACEI, Angiotensinconverting enzyme inhibitors; ARB, angiotensin II receptor blockers $\xi$, Microalbuminuria is defined as ACR $\geq 2.5 \mathrm{mg} / \mathrm{mmol}$ in male and $\geq 3.5 \mathrm{mg} / \mathrm{mmol}$ in female but $<25 \mathrm{mg} / \mathrm{mmol}$ in both genders; macroalbuminuria here is defined as $\geq 25 \mathrm{mg} / \mathrm{mmol}$ but $<150 \mathrm{mg} / \mathrm{mmol}$ in both genders. $\dagger,-2 \mathrm{log}$ likelihood without covariates $=4108.15$ and with covariates $=3909.48 ; \neq,-2 \log$ likelihood with covariates $=3897.88$; $\uparrow$, -2 log likelihood with covariates $=3879.21$.

on modifying these risk relationships as evidenced by changes in the HR plots of these risk factors. In particular, the risk association between blood $\mathrm{Hb}$ and $\mathrm{CHD}$ was entirely explained by eGFR and ACR while albuminuria and CKD had profound effects on the CHD risk association with HDL-C and TC.

\section{Lipid parameters}

The UKPDS reported graded increase in CHD risk with LDL-C in type 2 diabetes [3]. In our model, instead of LDL-C, TC was selected as a risk factor of CHD. More detailed analysis revealed complex interplay between lipid parameters, albuminuria, CKD and CHD risk in this large prospective cohort of type 2 diabetic patients with a broad range of renal function and albuminuria.
While we observed a near linear relationship between TC and $\mathrm{CHD}$, once ACR was fitted into the risk curve, this relationship was present only in patients with albuminuria. These findings concur with that from a large scale cross-sectional study in USA $(\mathrm{n}=17,702)$ which showed risk association between albuminuria and hypercholesterolemia (TC and LDL-C) in a graded fashion [10]. On the other hand, the linear association between CHD and TC at $\geq 5.0 \mathrm{mmol} / \mathrm{L}$ was mainly observed in patients without CKD. Using the non-linear approach, we further demonstrated that high HDL-C was associated with low CHD risk when HDL-C was $\geq 1.1 \mathrm{mmol} / \mathrm{L}$. However, for levels lower than $1.1 \mathrm{mmol} / \mathrm{L}$, the presence of albuminuria and, in particular, CKD markedly changed the shape of the risk curve to an 'A shaped' with a paradoxically positive association between CHD risk and HDL-C level, giving rise to a zenith value of $1.10 \mathrm{mmol} / \mathrm{L}$. These non-linear relation- 

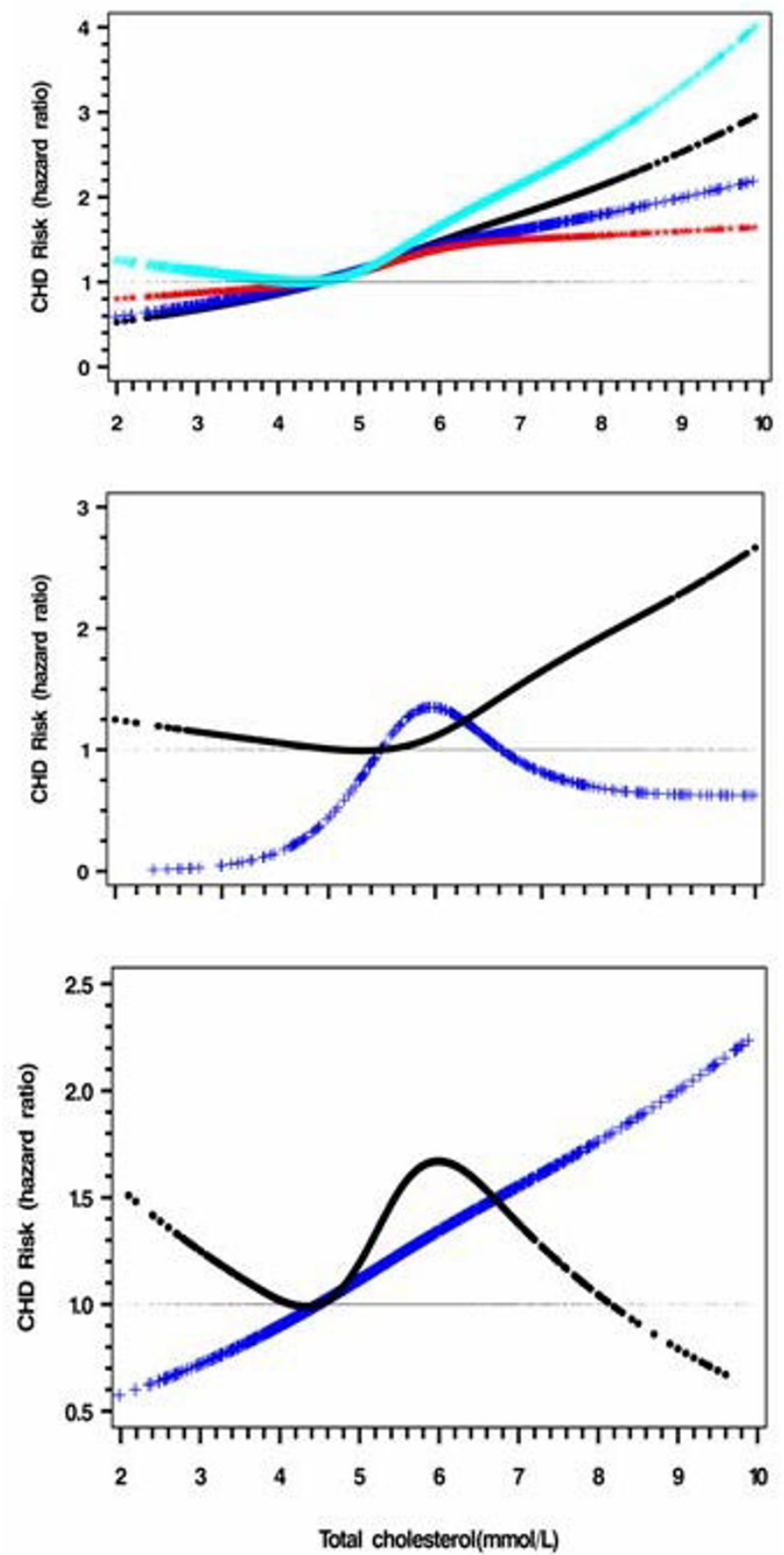

\section{Figure 2}

Full range risk associations between total cholesterol and CHD before and after adjustment for eGFR and ACR. a. Black: derived from model I ( $p<0.05)$; Blue: further adjusted for eGFR ( $<0.05)$; Red: further adjusted for eGFR and ACR ( $p<0.05)$; Cyan: limited to eGFR $\geq 60 \mathrm{ml} / \mathrm{min}$ per I.73 $\mathrm{m}^{2}$ in model I $(p<0.05)$. Model one variables include age, sex, and smoking status (current/exit), total cholesterol, HDL-C, Hb, eGFR and use of ACEI/ARB as well as use of insulin at enrolment. b. Black: adjusted curve in patients with eGFR $\geq 60 \mathrm{ml} / \mathrm{min}$ per $1.73 \mathrm{~m}^{2}(\mathrm{p}<0.05)$; Blue: adjusted curve in patients with eGFR $<60 \mathrm{ml} / \mathrm{min}$ per $1.73 \mathrm{~m}^{2}(p<0.05)$. c. Black: adjusted curve in patients without albuminuria $(p=0.080)$; Blue: adjusted curve in patients with albuminuria $(p<0.05)$. 

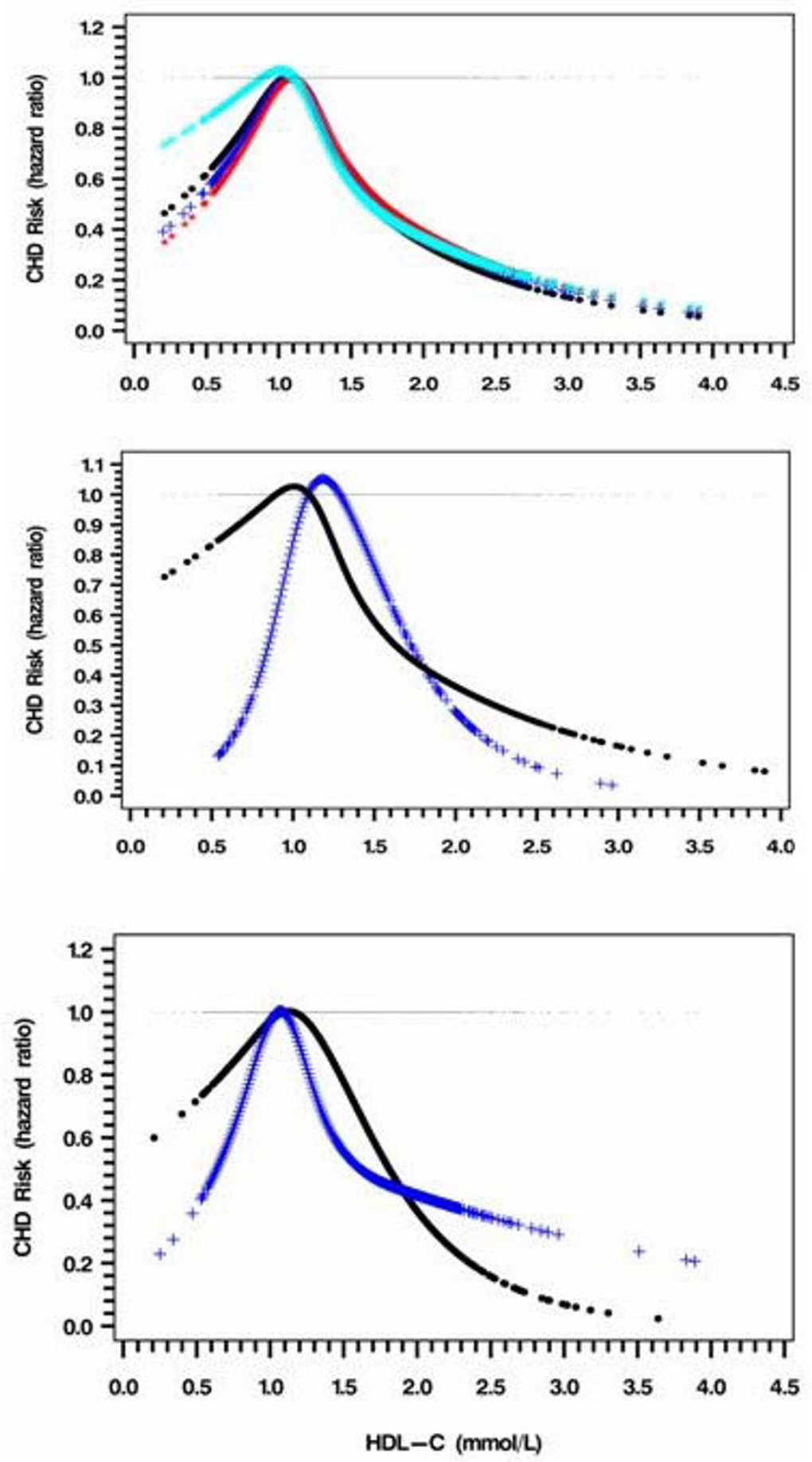

Figure 3

Full range risk associations between HDL-C and CHD before and after adjustment for eGFR and ACR. a. Black: derived from model I ( $p<0.05)$; Blue: further adjusted for eGFR ( $p<0.05)$; Red: further adjusted for eGFR and ACR ( $<<$ 0.05); Cyan: limited to eGFR $\geq 60 \mathrm{ml} / \mathrm{min}$ per $1.73 \mathrm{~m}^{2}$ in model I $(p<0.05$ ). Model one variables include age, sex, and smoking status (current/ex), total cholesterol, HDL-C, Hb, eGFR and use of ACEI/ARB as well as use of insulin at enrolment. The hazard ratio was calculated using the zenith as the reference level. b. Black: adjusted curve in patients with eGFR $\geq 60 \mathrm{ml} / \mathrm{min}$ per $1.73 \mathrm{~m}^{2}(p<0.05)$; Blue: adjusted curve in patients with eGFR $<60 \mathrm{ml} / \mathrm{min}$ per $1.73 \mathrm{~m}^{2}(\mathrm{p}<0.05)$. c. Black: adjusted curve in patients without albuminuria $(p<0.05)$; Blue: adjusted curve in patients with albuminuria $(p<0.05)$. 

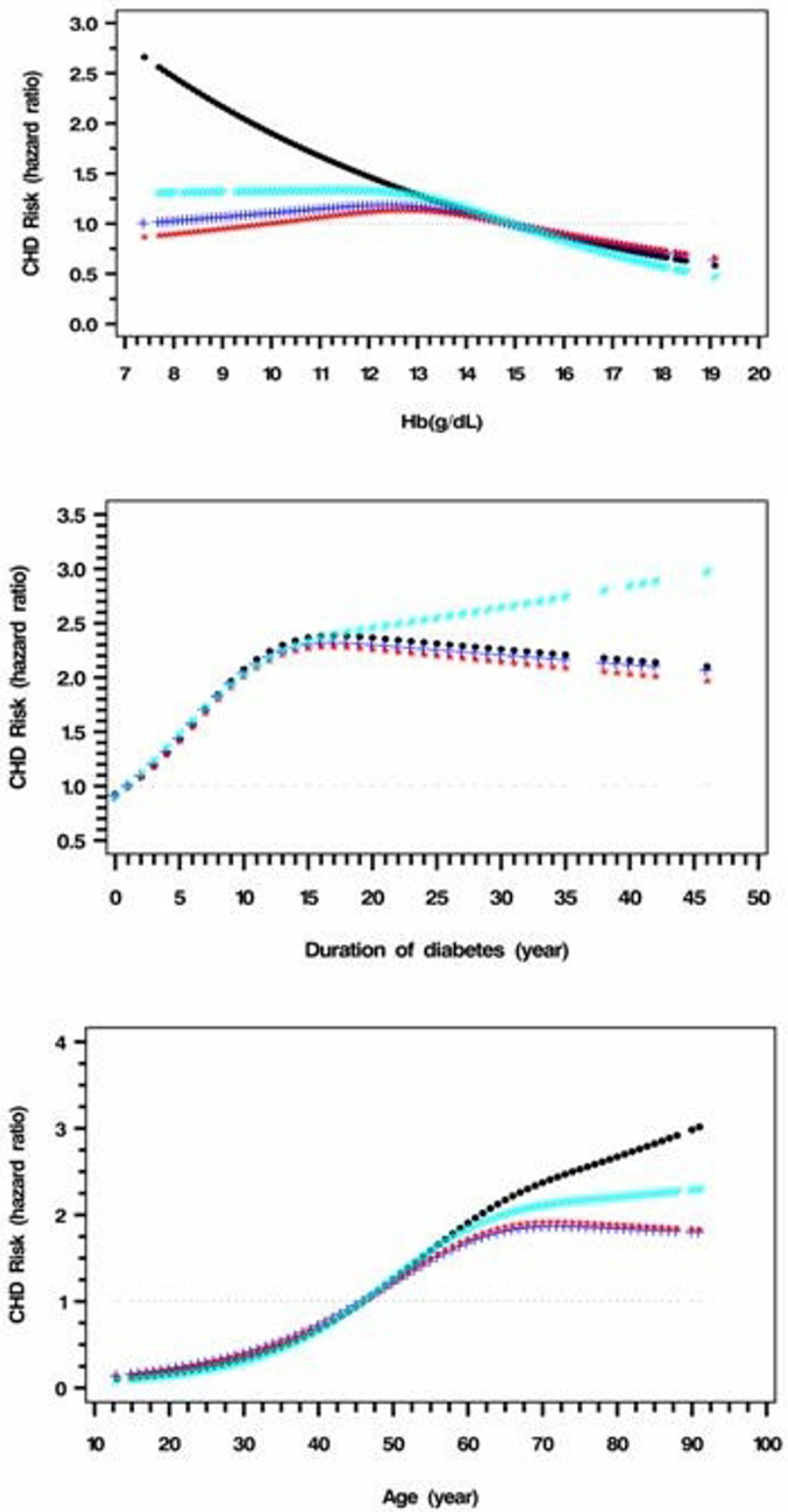

Figure 4

Full range risk associations between $\mathrm{CHD}$ and $\mathrm{Hb} /$ duration of diabetes/age before and after adjustment for eGFR and ACR. a. Black: adjusted for model I variables ( $p<0.05)$; Blue: further adjusted for eGFR (p: NS). Red: further adjusted for eGFR and ACR (p: NS); Cyan: limited to eGFR $\geq 60 \mathrm{ml} / \mathrm{min}$ per $1.73 \mathrm{~m}^{2}$ in model I $(p<0.05$ ). Model one variables include age, sex, and smoking status (current/ex), total cholesterol, HDL-C, Hb, eGFR and use of ACEI/ARB as well as use of insulin at enrolment. The hazard ratio was calculated using the $25^{\text {th }}$ percentiles, $75^{\text {th }}$ percentiles as the reference level. b. Black: adjusted for model I variables ( $p<0.05)$; Blue: further adjusted for eGFR $(p<0.05)$. Red: further adjusted for eGFR and ACR $(p<0.05)$; Cyan: limited to eGFR $\geq 60 \mathrm{ml} / \mathrm{min}$ per $1.73 \mathrm{~m}^{2}$ in model I $(p<0.05)$. c. Black: adjusted for model I variables ( $<<$ $0.05)$; Blue: further adjusted for eGFR ( $<<0.05)$. Red: further adjusted for eGFR and ACR ( $<0.05)$; Cyan: limited to eGFR $\geq 60 \mathrm{ml} / \mathrm{min}$ per $1.73 \mathrm{~m}^{2}$ in model I $(p<0.05)$ 
ships were further confirmed by conventional Cox regression analysis. Using $0.80-1.39 \mathrm{mmol} / \mathrm{L}$ as the referent, HDL-C $<0.80 \mathrm{mmol} / \mathrm{L}$ and HDL-C $\geq 1.4 \mathrm{mmol} / \mathrm{L}$ were both associated with reduced risk of CHD.

The nature of this positive association between HDL-C and CHD for HDL-C values less than $1.1 \mathrm{mmol} / \mathrm{L}$, observed mainly in patients with CKD or albuminuria requires further elucidation. However, in light of the potent anti-inflammatory and anti-oxidant properties of HDL-C particles $[21,22]$, we postulate that these associations may be due to changes in the metabolic milieu associated with CKD and severe albuminuria $[23,24]$.

Against these thought-provoking findings, it is noteworthy that in the recent 4D study, treatment with atorvastatin failed to reduce CHD risks in patients with ESRD [25]. These findings are not unexpected given the lack of association between LDL-C and CHD in patients with ESRD in epidemiological studies as well as the non-association between TC and CHD risk in our patients with CKD [12]. Furthermore, two recent clinical trials failed to confirm the hypothesis that increasing HDL-C can reduce the progression of coronary atherosclerosis [26,27]. Again, our findings regarding the powerful effects of albuminuria and $\mathrm{CKD}$ on altering the pattern of risk association between HDL-C and CHD highlight the complexity of interrelationships between energy metabolism and organ function.

\section{Blood haemoglobin, renal impairment and albuminuria}

Our group and others have reported the risk association of CHD with low eGFR $[11,28]$. In our current analysis, adjustment for ACR greatly attenuated the association between eGFR and CHD risk, suggesting that the risk association was in part mediated by albuminuria, a marker of endothelial dysfunction. In this cohort, we detected a sharp and linear association between CHD risk and ACR starting from 0 to $150 \mathrm{mg} / \mathrm{mmol}$. This observation therefore concord with findings by Gerstein et al showing that any degree of albuminuria is a risk factor for cardiovascular disease [29].

There is strong evidence showing that low blood $\mathrm{Hb}$ is a strong predictor for CHD [30,31]. In our analysis, the risk association between CHD risk and blood Hb was rendered non significant after adjustment for eGFR and exclusion of patients with CKD. These findings suggest that blood $\mathrm{Hb}$ may merely serve as a surrogate marker for CKD and thus may explain the negative results of two recent clinical trials which failed to confirm the beneficial effects of correction of anaemia using erythropoietin therapy on cardiovascular endpoints in patients with ESRD $[32,33]$.

\section{Other CHD risk factors}

In patients with diabetes less than 13 years, there was linear relationship between CHD risk and disease duration. In patients with disease more than 13 years, the statistical significance of disease duration disappeared. This may be confounded by the strong relationship between disease duration and albuminuria and that between albuminuria and hypercholesterolaemia $[9,10]$.

Age is a well-known risk factor of CHD [3]. However, our study suggests that this age-associated CHD risk was in part mediated by loss of renal function after the age of 55 years. In agreement with the UKPDS [3], we also found a risk-protecting effect of female gender on CHD. Smoking is a well-known risk factor of CHD which is also independently associated with CHD in our cohort [3].

Although there is strong epidemiological evidence supporting the risk association between CHD and glycemic control $[3,34]$, the UKPDS failed to confirm the benefits of improving glycemia on CHD rates in an interventional setting [35]. In our cohort, $\mathrm{HbA}_{1 \mathrm{c}}$ was a significant predictor for CHD with a HR of 1.07 for every $1 \%$ increase in $\mathrm{HbA}_{1 \mathrm{c}}(\mathrm{p}=0.0136)$ after controlling for age, sex, SBP and smoking status. However, this significance was rendered non significant once ACR, TC, HDL-C, or disease duration were adjusted for. Other studies have shown that improvement in glycemic control reduced albuminuria and hypercholesterolaemia [35-37]. Taken together, with the possible causal effect of albuminuria on hypercholesterolaemia [10], our findings suggest that the effect of $\mathrm{HbA}_{1 \mathrm{c}}$ on CHD risk is likely to be mediated through risk factors such as albuminuria and lipids.

Blood pressure is a strong risk factor for CHD in type 2 diabetes [3]. In our analysis, the age and sex adjusted hazard ratio of SBP for CHD was 1.23 (95\% CI: 1.07-1.18) per $10 \mathrm{mmHg}(\mathrm{p}<0.001)$. However, after adjusting for the spline term of ACR, the significance of SBP did not persist $(p=0.172)$. Removal of the use of ACEI/ARB in the spline Cox model (without ACR and eGFR), the spline term of SBP was significant $(p=0.007)$. These findings suggest that low BP and use of ACEI/ARB were associated with reduced risk of $\mathrm{CHD}$, largely mediated by albuminuria.

Similar to the findings from the UKPDS [3], BMI and waist circumference were not selected as risk factors of CHD in the model. The age and sex adjusted HRs were also not significant ( $\mathrm{p}=0.494$ for BMI and 0.182 for waist circumference). Although BMI has been implicated in albuminuria [9], the association between BMI and CHD may be confounded by other mediators such as dyslipidemia and inflammation. Besides, the prognostic signifi- 
cance of BMI in the presence of co-morbidities such as diabetes may become paradoxically reversed [38].

\section{Limitations}

This prospective cohort consists of a heterogeneous cohort of type 2 diabetic patients with a wide range of disease duration and risk factors. Although this heterogeneity and the use of single baseline values may theoretically reduce the precision of these risk estimations, this draw back was partly compensated by the relatively large number of clinical events, detailed phenotyping at baseline and long period of observation. Overall, results generated from both conventional and non-linear approaches are robust and consistent which have generated alternative hypotheses which are biologically plausible. Further clinical and experimental studies are required to confirm these findings.

\section{Conclusions and Implications}

Using a large prospective database and relatively novel and robust statistical methods, we have found a strong linear association between TC and CHD only in patients with albuminuria. Adjusting for eGFR and albuminuria attenuated the associations between lipid, $\mathrm{Hb}, \mathrm{BP}$, duration of diabetes and $\mathrm{CHD}$, suggesting that albuminuria plays a linking role between these risk factors and CHD. The onset of CKD further changes risk associations between lipids (such as TC and HDL-C) and CHD. Recently, several major randomised clinical trials have yielded negative results regarding the effects of correcting anemia and reducing LDL-C on cardiovascular outcomes in patients with ESRD as well as that of raising HDL-C on reducing progression of atherosclerosis.

Based on these observations, we infer the following pathways to CHD in type 2 diabetes: 1). Hyperglycaemia and hypertension lead to albuminuria, a marker of endothelial and renal damage; 2). Albuminuria leads to hyperlipidaemia which further increases the risk of CHD; and 3). Albuminuria, both as a surrogate for multiple risk factors and causal factors, leads to deterioration of renal function and 5). Reduced renal function further changes the pattern of risk association between HDL-C and CHD, i.e., the predictive value of very low HDL-C $(<0.8 \mathrm{mmol} / \mathrm{L})$ no longer holds when CKD has developed.

Understanding the complex relationships among risk factors of CHD in type 2 diabetes is an important step towards further reducing CHD risk in type 2 diabetes. For example, reducing albuminuria might further control hyperlipidaemia and enhance the benefits of controlling traditional risk factors such $\mathrm{HbA}_{1 c^{\prime}} \mathrm{BP}$ and LDL-C. Our data also suggest that retarding rate of deterioration of renal function and correcting anaemia may have important cardioprotective effects. However, these hypotheses will need to be confirmed by both experimental and interventional studies.

\section{Abbreviations}

ACEI: Angiotensin-converting enzyme inhibitor;

ACR: Albumin: creatinine ratio;

ARB: Angiotensin II receptor blockers;

BMI: Body mass index;

CHD: Coronary heart disease;

CKD: Chronic kidney disease;

eGFR: Estimated glomerular filtration rate;

ESRD: End-stage renal disease;

Hb: Haemoglobin;

$\mathrm{HbA}_{1 \mathrm{c}}$ : Glycated haemoglobin;

HR: Hazard ratio;

HDL-C: High density lipoprotein cholesterol;

ICD-9: International Classification of Diseases, Ninth Revision;

LDL-C: Low-density-lipoprotein cholesterol;

MDRD: Modification of Diet in Renal Disease;

PAD: Peripheral arterial disease;

RCS: Restricted Cubic Spline;

UKPDS: United Kingdom Prospective Diabetes Study;

SCR: Serum creatinine;

SBP/DBP/BP: Systolic/diastolic blood pressure;

TC: Total cholesterol;

TG: Triglyceride;

WBC: White blood cell.

\section{Competing interests}

The author(s) declare that they have no competing interests. 


\section{Authors' contributions}

XLY performed the statistical analysis and drafted the manuscript. JC, RM, WS, GK, AK, CSC, PT and GC were involved in study design, coordination and data acquisition. VW, CL and CSH facilitated retrieval of laboratory data and clinical outcomes. All authors have read and approved the final manuscript.

\section{Acknowledgements}

This study was partially supported by the Hong Kong Foundation for Research and Development in Diabetes and the Li Ka Shing Institute of Health Sciences, the Chinese University of Hong Kong.

\section{References}

I. Murray CJ, Lopez AD: Mortality by cause for eight regions of the world: Global Burden of Disease Study. Lancet 1997, 349: $1269-1276$.

2. Laakso M: Cardiovascular disease in type 2 diabetes: challenge for treatment and prevention. J Intern Med 200I, 249:225-235.

3. Turner RC, Millns H, Neil HA, Stratton IM, Manley SE, Matthews DR, Holman RR: Risk factors for coronary artery disease in noninsulin dependent diabetes mellitus: United Kingdom Prospective Diabetes Study (UKPDS: 23). BMJ 1998, 316(1734):823-828.

4. de Zeeuw D, Remuzzi G, Parving HH, Keane WF, Zhang Z, Shahinfar S, Snapinn S, Cooper ME, Mitch WE, Brenner BM: Albuminuria, a therapeutic target for cardiovascular protection in type 2 diabetic patients with nephropathy. Circulation 2004, I 1 0:921-927.

5. Wang Z, Hoy WE: Albuminuria and incident coronary heart disease in Australian Aboriginal people. Kidney Int 2005, 68:1289-1293.

6. Yuyun MF, Khaw KT, Luben R, Welch A, Bingham S, Day NE, Wareham $\mathrm{NJ}$ : A prospective study of microalbuminuria and incident coronary heart disease and its prognostic significance in a British population: the EPIC-Norfolk study. Am J Epidemiol 2004, 1 59:284-293.

7. Rutter MK, Wahid ST, McComb JM, Marshall SM: Significance of silent ischemia and microalbuminuria in predicting coronary events in asymptomatic patients with type 2 diabetes. J Am Coll Cardiol 2002, 40:56-6I.

8. de Zeeuw D, Parving HH, Henning RH: Microalbuminuria as an early marker for cardiovascular disease. J Am Soc Nephrol 2006, I 7:2100-2105

9. Cederholm J, Eliasson B, Nilsson PM, Weiss L, Gudbjornsdottir S: Microalbuminuria and risk factors in type $I$ and type 2 diabetic patients. Diabetes Res Clin Pract 2005, 67:258-266.

10. Shankar A, Klein R, Moss SE, Klein BE, Wong TY: The relationship between albuminuria and hypercholesterolemia. I Nephrol 2004, I 7:658-665.

II. So WY, Kong AP, Ma RC, Ozaki R, Szeto CC, Chan NN, Ng V, Ho CS, Lam CW, Chow CC, Cockram CS, Chan JC, Tong PC: Glomerular filtration rate, cardiorenal end points, and all-cause mortality in type 2 diabetic patients. Diabetes Care 2006, 29:2046-2052.

12. Kaysen GA: Dyslipidemia in chronic kidney disease: Causes and consequences. Kidney Int 2006, 70:S55-S58.

13. Piwernetz K, Home PD, Snorgaard O, Antsiferov M, Staehr-Johansen K, Krans M: For the DiabCare Monitoring Group of the St. Vincent Declaration Steering Committee. Monitoring the targets of the St. Vincent declaration and the implementation of quality management in diabetes care: the DiabCare initiative. Diabet Med 1993, 10:37I-377.

14. Laakso M, Pyorala K: Age of onset and type of diabetes. Diabetes Care 1985, 8: II4-117.

15. So WY, Ozaki R, Chan NN, Tong PC, Ho CS, Lam CW, Ko GT, Chow CC, Chan WB, Ma RC, Chan JC: Effect of angiotensin-converting enzyme inhibition on survival in 3773 Chinese type 2 diabetic patients. Hypertension 2004, 44:294-299.

16. Yang XL, So WY, Kong AP, Clarke P, Ho CS, Lam CW, Ng MH, Lyu RR, Yin DD, Chow CC, Cockram CS, Tong PC, Chan JC: End-stage renal disease risk equations for Hong Kong Chinese patients with type 2 diabetes: Hong Kong Diabetes Registry. Diabetologia 2006, 49:2299-2308.

17. Ma YC, Zuo L, Chen JH, Luo Q, Yu XQ, Li Y, Xu JS, Huang SM, Wang LN, Huang W, Wang M, Xu GB, Wang HY: Modified glomerular filtration rate estimating equation for Chinese patients with chronic kidney disease. J Am Soc Nephrol 2006, 17:2937-44.

18. Harrell F: Regression Modelling Strategies with applications to Linear Models, Logistic Regression, and Survival Analysis New York: Spinger-Varlag New York, Inc; 200I.

19. So WY, Yang XL, Ma RC, Kong AP, Lam CW, Ho CS, Cockram CS, Ko GT, Chow CC, Wong V, Tong PC, Chan JC: Risk factors in Vshaped risk associations with all-cause mortality in type 2 diabetes -The Hong Kong Diabetes Registry. Diabetes Metab Res $\operatorname{Rev} 2007$ [http://www3.interscience.wiley.com/cgi-bin/ home?CRETRY $=$ I\&SRETRY $=0$ ]. Published online in Wiley InterScience. DOI: $10.1002 / \mathrm{dmrr} .792$

20. Lin DY, Wei LJ, Ying Z: Checking the Cox Model with Cumulative Sums of Martingale-Based Residuals. Biometrika 1993, 80:557-572.

21. Barter PJ, Nicholls S, Rye KA, Anantharamaiah GM, Navab M, Fogelman AM: Antiinflammatory properties of HDL. Circ Res 2004, 95:764-772.

22. Chapman MJ: Therapeutic elevation of HDL-cholesterol to prevent atherosclerosis and coronary heart disease. Pharmacol Ther 2006, I I I:893-908.

23. Locatelli F, Pozzoni P, Tentori F, del Vecchio L: Epidemiology of cardiovascular risk in patients with chronic kidney disease. Nephrol Dial Transplant 2003, I8(Suppl 7):vii2-9.

24. Wong CK, Ho AW, Tong PC, Yeung CY, Kong AP, Lun SW, Chan JC, Lam CW: Aberrant activation profile of cytokines and mitogen-activated protein kinases in type 2 diabetic patients with nephropathy. Clin Exp Immunol 2007, I49(I):|23-I3I. doi:10.1 III/j.I365-2249.2007.03389.x

25. Wanner C, Krane V, Marz W, Olschewski M, Mann JF, Ruf G, Ritz E, German Diabetes and Dialysis Study Investigators: Atorvastatin in patients with type 2 diabetes mellitus undergoing hemodialysis. N Engl J Med 2005, 353:238-248.

26. Nissen SE, Tardif JC, Nicholls SJ, Revkin JH, Shear CL, Duggan WT, Ruzyllo W, Bachinsky WB, Lasala GP, Tuzcu EM, ILLUSTRATE Investigators: Effect of torcetrapib on the progression of coronary atherosclerosis. N EnglJ Med 2007, 356: I 304-1316.

27. Kastelein JJ, van Leuven SI, Burgess L, Evans GW, Kuivenhoven JA, Barter PJ, Revkin JH, Grobbee DE, Riley WA, Shear CL, Duggan WT, Bots ML, RADIANCE I Investigators: Effect of Torcetrapib on Carotid Atherosclerosis in Familial Hypercholesterolemia. N Engl J Med 2007, 356: 1620-1630.

28. Henry RM, Kostense PJ, Bos G, Dekker JM, Nijpels G, Heine RJ, Bouter LM, Stehouwer CD: Mild renal insufficiency is associated with increased cardiovascular mortality: The Hoorn Study. Kidney Int 2002, 62: I 402-1407.

29. Gerstein HC, Mann JF, Yi Q, Zinman B, Dinneen SF, Hoogwerf B, Halle JP, Young J, Rashkow A, Joyce C, Nawaz S, Yusuf S, HOPE Study Investigators: Albuminuria and risk of cardiovascular events, death, and heart failure in diabetic and nondiabetic individuals. JAMA 200I, 286:42I-426.

30. Jurkovitz CT, Abramson JL, Vaccarino LV, Weintraub WS, McClellan WM: Association of high serum creatinine and anemia increases the risk of coronary events: results from the prospective community-based atherosclerosis risk in communities (ARIC) study. J Am Soc Nephrol 2003, 14:2919-2925.

31. Levin A: Cardiac disease in chronic kidney disease: current understandings and opportunities for change. Blood Purif 2004, 22:21-27.

32. Drueke TB, Locatelli F, Clyne N, Eckardt KU, Macdougall IC, Tsakiris $D$, Burger HU, Scherhag A, CREATE Investigators: Normalization of hemoglobin level in patients with chronic kidney disease and anemia. N Engl J Med 2006, 355:207|-2084.

33. Singh AK, Szczech L, Tang KL, Barnhart H, Sapp S, Wolfson M, Reddan D, CHOIR Investigators: Correction of anemia with epoetin alfa in chronic kidney disease. N Engl J Med 2006, 355:2085-2098.

34. Lehto S, Ronnemaa T, Haffner SM, Pyorala K, Kallio V, Laakso M: Dyslipidemia and hyperglycemia predict coronary heart disease events in middle-aged patients with NIDDM. Diabetes 1997, 46:1354-1359.

35. UK Prospective Diabetes Study (UKPDS) Group: Intensive bloodglucose control with sulphonylureas or insulin compared 
with conventional treatment and risk of complications in patients with type 2 diabetes (UKPDS 33). Lancet 1998, 352:837-853.

36. The Diabetes Control and Complications Trial Research Group: The effect of intensive treatment of diabetes on the development and progression of long-term complications in insulindependent diabetes mellitus. $N$ Engl J Med 1993, 329:977-986.

37. Yanagawa T, Araki A, Sasamoto K, Shirabe S, Yamanouchi T: Effect of antidiabetic medications on microalbuminuria in patients with type 2 diabetes. Metabolism 2004, 53:353-357.

38. Ko GT, So WY, Chan NN, Chan WB, Tong PC, Li J, Yeung V, Chow CC, Ozaki R, Ma RC, Cockram CS, Chan JC: Prediction of cardiovascular and total mortality in Chinese type 2 diabetic patients by the WHO definition for the metabolic syndrome. Diabetes Obes Metab 2006, 8:94-104.

Publish with Biomed Central and every scientist can read your work free of charge

"BioMed Central will be the most significant development for disseminating the results of biomedical research in our lifetime. "

Sir Paul Nurse, Cancer Research UK

Your research papers will be:

- available free of charge to the entire biomedical community

- peer reviewed and published immediately upon acceptance

- cited in PubMed and archived on PubMed Central

- yours - you keep the copyright

Submit your manuscript here:

http://www.biomedcentral.com/info/publishing_adv.asp
BioMedcentral 